\title{
Erratum to: Virasoro and KdV
}

\section{Francisco J. Plaza Martín' ${ }^{1}$ - Carlos Tejero Prieto ${ }^{1}$}

\section{Erratum to: Lett Math Phys DOI 10.1007/s11005-016-0924-9}

The original version of this article unfortunately contained a mistake. The family name of the second author was listed in reverse order as "Prieto Tejero". The correct version of the family name is given here.

The original article was corrected.

The online version of the original article can be found under doi:10.1007/s11005-016-0924-9.

Francisco J. Plaza Martín fplaza@usal.es

Carlos Tejero Prieto carlost@usal.es

1 Departamento de Matemáticas and IUFFyM, Universidad de Salamanca, Plaza de la Merced 1, 37008 Salamanca, Spain 